\title{
SENTIDOS DOS TEMPOS NA RELAÇÃO MUSEU/ESCOLA
}

\author{
Júnia Sales Pereira* \\ Marcus Vinicius Corrêa Carvalho*
}

\begin{abstract}
Educadora de Museu: - Agora vocês verão um objeto que era utilizado há muito e muito tempo atrás na escola: o mimeógrafo!

Aluno: - Professor, será que a nossa escola "parou" no tempo?

Professor: - Gente, depois nós conversaremos a respeito...
\end{abstract}

\begin{abstract}
RESUMO: Neste texto apresentamos reflexões a respeito da questão da processualidade dos tempos históricos na relação museu-escola, sinalizando para a relevância dos estudos sobre a memória, a história e o esquecimento para qualificar esta discussão. A relação pedagógica estabelecida com o museu é compreendida como parte de um processo educativo que não se encerra na visitação museal, mas atravessa esse momento, buscando compreender a dinâmica da dimensão formativa desta interação em que o protagonismo e a criatividade dos sujeitos envolvidos são considerados como fatores determinantes.
\end{abstract}

Palavras-chave: Ensino de História. Escola. Museu. Tempo. Memória.

MEANINGS OF TIMES IN THE MUSEUM-SCHOOL RELATIONSHIP

ABSTRACT: This paper reflects on how historical time is processed in the museum-school relationship. It points out the relevance of studies on memory, history and forgetfulness to qualify

* Doutora em História e professora da Faculdade de Educação da Universidade Federal de Minas Gerais (UFMG). E-mail: juniasales@gmail.com

** Doutor em História e professor da Faculdade de Educação da Universidade Estadual de Minas Gerais (UEMG). E-mail: marcus.fae.uemg@gmail.com 
this discussion. The pedagogical relationship established with museums is understood as part of an educational process that does not end with the visits, but exceeds them. The text tries to comprehend the dynamics and formative dimension of this interaction in which the subjects' creativity and protagonism seem to be determining factors.

Key words: History Teaching. School. Museum. Time. Memory.

\section{Das totalidades ao prisma}

e considerarmos plausível a assertiva de que o museu é uma morada de dispersões temporais, corporais e simbólicas, compreenderemos que o objeto cultural recebe nele nova e diversa hospitalidade. Como na vida social, o museu é compreendido pela pluralização movente de sentidos, conferidos e subvertidos a cada visita, posto que o campo da recepção é, também ele, diverso e criativo.

O museu é ambiente em que reside a interrelação das percepções sociais diversas, guardando uma variedade de gestos preservacionistas, silenciamentos, monumentalizações, perspectivas historiográficas e museológicas, bem como intençôes educativas, turísticas e celebrativas, instaurando uma miríade de oportunidades formadoras para a percepção dos múltiplos sentidos dos tempos - e, neles, o que há de história, de memória e de esquecimento.

O museu singulariza os objetos: dá a eles um tratamento específico, criando uma nova "posição" para os mesmos (Heidegger, 1999). Compõem-se, então, narrativas a partir da seleção arbitrada para a entrada de objetos no museu. Nele, há objetos postos em relação espaço-temporal determinada, a partir de recursos de cenografia, como paredes vazias, suportes, plataformas, luzes, sons, e há planejamento do trabalho de visitação. Nesses processos, estão em jogo concepções sobre o tempo que nem sempre são confluentes, planejadas ou previsíveis, nem mesmo evidentes, variando em temporalidades moventes e/ou estanques.

Muitos museus são erigidos a partir do suposto da totalidade cultural, pretendendo encenar os sentidos unívocos do tempo histórico e toda a história nele implicada. Há neles insistência na representação verdadeira encarnada nas mais significativas imagens, corpos e discursos rituais. 
Diversamente, os museus podem ser compreendidos como instituições através das quais é possível o cruzamento de fronteiras em direção a outras aprendizagens e discursos sobre a história e os tempos, sendo capazes de estimular o visitante a buscar outras representações. Assim, os museus são compreendidos como instituição-prisma, em que há disseminação de uma infinidade de novos signos, sendo movente pelo trabalho que realiza em contato com públicos diferenciados. Para além da totalidade suposta, o museu ofertar-nos-ia a oportunidade de capturar mutáveis percepçôes de seu sentido social e cultural.

\section{Da evasão dos tempos à tensão hermenêutico-temporal}

A tese da evasão, como estratégia de fuga da irreversibilidade temporal, é um aspecto pertinente à reflexão sobre a experiência museal, pelo menos na medida em que esta experiência se manifesta como proposta de abranger a totalidade histórica e cultural, encerrando-a no momento presente, supostamente vinculando o atual e o eterno. A encarnação em objetos, imagens, corpos e discursos de um tempo que, passado, eterniza-se na atualização ritual, desloca a experiência do sentido da história para uma dimensão de terror e fuga, em que se cristaliza uma identidade com o devir que pretende tornar opaca, e por isso suportável, a consciência da finitude humana.

Parece pertinente perguntarmo-nos sobre a capacidade dessa noção de evasão em definir o sentido geral das relações com o tempo e a história na experiência museal. O evadir-se do tempo, e do terror da irreversibilidade, é uma das relações possíveis com as temporalidades múltiplas implicadas na consciência espaço-temporal dos humanos em suas experiências históricas vividas, mas certamente não é a única.

Fernand Braudel, pensando a história como uma "dialética da duração", talvez estivesse vinculado à evasão e ao terror, na medida em que pretendia situar a história em três "diferentes níveis": o episódico, o de meia profundidade e o estrutural. Porém, ele não deixava de entender tal proposição como uma simplificação do problema. "A história situa-se em diferentes níveis, quase diria em três níveis, se isso não fosse simplificar demasiado: são dez, cem níveis aqueles que haveria que considerar, dez, cem durações diferentes” (Braudel, 1982, p. 80). 
Dada a imensa complexidade de sua apreensão e reflexão, os tempos e as temporalidades exigem o recurso a elementos de abordagem indireta, como sejam os acontecimentos, como pretendia Braudel, ou as narrativas, como pretendia Paul Ricouer em seu Temps et récit. Este autor apontou para o vasto espectro de possibilidades de abordagem do tema já em sua introdução ao livro Le temps et les philosophies, acentuando a multiplicidade de discursos sobre o tempo que a obra encerrava: de uma visada dos filósofos analíticos ingleses preocupados com a "economia conceitual", até uma outra do pensamento meditativo, atenta à "intensidade espiritual" (Ricoeur, 1978, p. 11).

Porosidades de fronteiras espaço-temporais, justaposiçōes, interpenetrações e imbricações de percepção das durações, multiplicidade de sensações, infinidade de apreensões e interpretações são noções que devem ser mantidas em horizonte quando refletimos sobre este tema. Podemos conceber, a princípio, uma rede que se move para todos os lados, criando linearidades fractais que, em conjunto, promovem a percepção de uma intrincada junção que emerge em contextos específicos, permitindo a elaboração de um sentido processual complexo.

Martin Heidegger criticava o fato do "tempo" funcionar como critério ôntico para a distinção das diversas regiōes dos entes, distinguindo processos naturais e acontecimentos históricos, como entes do âmbito "temporal", das relações numéricas e espaciais que constituiriam entes do "não temporal" (Heidegger, 1988, p. 46). Para entendêlo, basta lembrar que até o surgimento da filosofia na Grécia, no século IV a.C., o verbo ser não ocorria de modo classificatório, como constatou Eric A. Havelock em sua análise do Canto I da Ilíada, de Homero (apud Vieira, 1994). É exatamente o surgimento de uma definição "daquilo que é continuamente", como essencialidade e permanência, uma das condiçôes que permitiram a Platão fundar uma ontologia, isto é, um discurso sobre o "que verdadeiramente é" (Lopes, 2002, p. 17).

Podemos compreender assim a proposta heideggeriana da "tarefa de uma destruição da história da ontologia”, traduzida como crítica que assinala a historicidade como modo temporal próprio da "pre-sença". Ao pensar a tradição e explicar o que ela "lega”" e como o faz, a "pre-sença” se assume no modo de ser do questionamento e da pesquisa dos fatos historiográficos. A historicidade desta presentificação torna-se objeto de análise não mais como uma essencialidade contínua daquilo que se 
apresenta, mas como elemento-chave da própria definição daquilo que é como pre-sença (Heidegger, 1988, p. 47-49). Grosso modo, diríamos que a definição "ôntica-ontológica" daquilo que dizemos que é tem historicidade. Acompanhemos as palavras de Heidegger (1988, p. 82) para perceber o alcance do problema:

Uma das primeiras tarefas da analítica será, pois, mostrar que o princípio de um eu e sujeito, dados como ponto de partida, deturpa, de modo fundamental, o fenômeno da pre-sença. Toda ideia de "sujeito" - enquanto permanência não esclarecida preliminarmente mediante uma determinação ontológica de seu fundamento - reforça, do ponto de vista ontológico, o ponto de partida do subjectum, por mais que, do ponto de vista ôntico, se possa arremeter contra a "substância da alma" ou a "coisificação da consciência". Para que se possa perguntar o que deve ser entendido positivamente ao se falar de um ser não coisificado do sujeito, da alma, da consciência, do espírito, da pessoa, é preciso já se ter verificado a proveniência ontológica da coisificação. Todos esses termos designam regiōes de fenômenos determinadas e passíveis de "formação plena", embora o seu uso ocorra sempre junto a uma curiosa indiferença frente à necessidade de se questionar o ser dos entes assim denominados. (Grifos do autor)

A crítica heideggeriana estende-se à própria fundamentação epistemológica da antropologia, da psicologia, da biologia e, por que não, da historiografia. Afinal, a própria definição do "sujeito" de conhecimento é posta em cheque na medida em que é pensada em uma definição "ôntica-ontológica" como entidade que continuamente é. "Ao invés de questioná-lo, concebeu-se o ser do homem como 'evidência', no sentido de ser simplesmente dado junto às demais coisas criadas [divinamente]" (Heidegger, 1988, p. 86). Heidegger aponta para os limites da historicidade como formulada no pensamento epistemológico do historiador da cultura Wilhelm Dilthey, tanto em sua problemática como em sua conceituação, bem como para "todas as correntes do 'personalismo" determinadas por ele e por Henri Bergson - além de "todas as tendências para uma antropologia filosófica” (idem, ibid., p. 83).

Em suma, o parti pris irrefletido da própria constituição "ônticaontológica" do sujeito de conhecimento deturparia a possibilidade mesma do conhecer. "A possibilidade de se dominar a multiplicidade variada dos fenômenos num quadro de conjunto não assegura uma compreensão real do que é assim ordenado" (idem, ibid., p. 89). 
O deslocamento operado do sentido e do significado da historicidade, que migra de um lugar essencializado para outro em que sentido e significado se constroem na dinâmica da própria relação sujeito/ objeto, sugere uma chave interpretativa em que a complexidade dos sentidos de temporalidade postos em jogo não pode ser deixada de lado, se o que se pretende é perceber a emergência dinâmica das possibilidades de conhecimento histórico através da relação museu/escola.

Voltemos ao exemplo do mimeógrafo. Longe de ser um objeto do "passado", ele é compreendido como um elemento de problematização do entrecruzamento de múltiplos tempos. Ele nos remete a temporalidades e práticas dinâmicas e complexas, social e culturalmente instituídas. É possível que esse mesmo objeto, considerado "preso" a um determinado período, seja problematizado em sua diversidade de usos sociais e culturais do "passado", do "presente" e até do "futuro".

A visita educativa ao museu cria oportunidade para discutir a transformação dos objetos e seus usos no tempo, mas também cria uma oportunidade para a reflexão acerca do discurso do museu sobre os objetos. Por que razões a educadora do museu supõe não existirem mais mimeógrafos em uso nas escolas? Diversamente do que supõe o aluno, de que sua escola estaria - como o próprio objeto que opera - "parada" no tempo, é possível complexificar a compreensão da dinâmica de transformação dos objetos para além da linearidade passado-presentefuturo.

Se concebermos a historicidade não como essencialidade que "é continuamente" e define aquilo que "verdadeiramente é", mas percebermos as porosidades de fronteiras espaço-temporais, as justaposiçōes, as interpenetrações e as imbricaçôes de percepção das duraçôes, bem como a infinidade de apreensōes e interpretaçōes nela implicadas, seremos capazes de manter em nosso horizonte de aprendizado a complexidade intrínseca à própria experiência espaço-temporal.

Poderemos perceber as limitações da concepção históricomuseológica dos museus erigidos a partir do suposto da totalidade cultural - que encenam os sentidos unívocos do tempo histórico e de toda a história nele implicada -, acenando com a mesma crítica de Andy Clark àquilo que guarda a expressão "total state". As explicações abrangidas pelo conceito de "total state" não seriam capazes de compreender os sistemas em que o fluxo de informaçōes complexas tem um 
papel-chave (Clark, 2008). Não é ocioso sugerir atenção ao desenvolvimento da teoria dos sistemas dinâmicos e daquilo que Clark classifica como teatro heideggeriano.

O alvo de Clark "não é apenas um sistema de controle neural, mas uma economia cognitiva complexa, ligando cérebro, corpo e mundo". Uma economia complexa na qual o corpo ocupa um papel crucial, posto que ele é o órgão da percepção ativa na medida em que autoestrutura as informações, permitindo a estruturação que suporta uma variedade de extensões de organização de solução de problemas. $\mathrm{O}$ corpo é o teatro heideggeriano: "o lugar onde tudo se ajunta, o tanto quanto seja possível tal junção" (Clark, 2008, p. 217). Esse processo formativo dá ao corpo a fluência que o permite tornar acessível o mundo como uma espécie de arena não mediatizada para a ação corpórea. $\mathrm{O}$ mundo extracorpóreo equilibra-se, ganha sentido e/ou forma, para ser apresentado ao agente não apenas como um problema espacial, mas também como um recurso de solução de problemas e de aprendizado.

Nessas interações, o corpo é um lugar no qual nós podemos agir fluentemente em caminhos que simplificam ou transformam os problemas que queremos resolver. O corpo torna-se, na concepção de Clark, aquilo que Heidegger chamou de "equipamento transparente" (apud Clark, op. cit., p. 10). É como se o agente enxergasse através do equipamento o artefato que produz. "A caneta em uso não é o foco de nossa atenção, como não o é a mão que a segura. Ambas são transparentes" - pelo menos até que acabe a tinta ou a mão se canse (idem, ibid.). A teoria dos sistemas dinâmicos e a crítica heideggeriana à história da ontologia assinalam a necessidade de mantermos em horizonte a complexidade que envolve os tempos e as temporalidades, seja nas relações estabelecidas nas visitas educativas ao espaço museal, seja nas interpretações históricas ou em qualquer atividade cognitiva. Parece crucial manter em foco a tensão hermenêutico-temporal, se pretendemos que nosso trato com o passado ultrapasse a simples coincidência entre ele e nossos desejos, vislumbrando uma experiência formativa em que a interação com o mundo - por exemplo, em uma visita a uma exposição museal - seja mais que o resultado de um processo de formação alienado da dimensão ética (Adorno, 1995, passin).

Pensemos em uma estrutura emergente e dinâmica que consolida determinada percepção da realidade em contextos específicos por 
frequência de trato e uso, nos quais emergem as diversas referências de tempo em rede que só fazem sentido na multiplicidade da abordagem contextual do processo mesmo de emergência. A relação museu-escola pode manter em horizonte uma educação como aprendizado aberto à elaboração cotidiana da história e ao exercício de contato com o não idêntico.

\section{Os tempos e os objetos multiplicados}

A posição que o objeto ocupa no museu é, em alguma medida, instável. A visita educativa tanto manifesta quanto esconde uma série infinita de relações situadas no contexto da experiência museal, pondo em contato de maneira fugaz as "carnes do mundo" (Merleau-Ponty, 2000 , passin), num horizonte que comporta zonas claras, focos de luz e obscuridades. Estão postos em relação, mediados pela ambiência do museu, os objetos, as palavras, os sons e os silêncios na urdidura das exposiçōes, bem como a voluptuosidade física e a encenação, além das cadências e dos ritmos impressos pela caminhada errante do visitante e pelas distâncias entre os corpos.

O que é exposto no museu integra uma intrincada história de seleção para os modos da visibilidade e para os do esquecimento. As ideias e as carnes em exposição são, dessa maneira, anteparos (idem, ibid.) porque enunciam histórias, mas também nos impedem de perceber as múltiplas articulações temporais e corpóreas da vida. Toda visão é constituída por alargamento de alguns horizontes e por anteparo de outros.

Talvez essa compreensão pacifique o desejo da visita total ao museu, a qual teria como resultado miraculoso o aprendizado de todas as coisas numa só caminhada. Não há visibilidade absolutamente apreensível dos tempos históricos, como não há também invisibilidade plena. Há horizontes de aprendizado e sensibilização histórica sempre restritos numa visita educativa.

O que importa no caso da relação museu-escola é o alargamento da ideia de museu pelo professor, compreendendo as ilusóes implicadas na suposição da visita total, a pretensão de apreensão plena de significados históricos ou da aprendizagem da história como sucessão cadenciada, organizada e previsível dos tempos. Trata-se de uma aprendizagem de uso do museu para além da notícia da história dos objetos que 
ele guarda, convidando ao exercício de reflexão sobre a história do museu e do seu papel social, enfatizando suas armadilhas de concepção e exposição museológica, inclusive, considerando seu jogo político no plano da cultura.

O museu é visto como local de uma relação educativa iminente, dependente da capacidade criadora dos sujeitos em problematizar seus limites e seus interesses; sem o que haveria, apenas, uma possibilidade latente, mal desdobrada, de uma relação fundamentalmente educativa.

O que fazer numa visita educativa de 50 minutos, com 50 alunos e dois mil objetos expostos numa rede discursiva previamente arbitrada? Nesse caso, nem os objetos podem ser conhecidos ou reconhecidos se não há uma chave interpretativa definida para ser utilizada pelos sujeitos envolvidos nesta relação. O que se realiza é mais uma “impressão de passagem" em um determinado percurso pelo museu, não possibilitando qualquer aprendizagem e/ou sensibilização propriamente histórica.

A partir da percepção do objeto-fragmento haverá tão somente descontinuidades, sem a possibilidade factível da criação de ideias acerca da processualidade dos objetos e/ou da própria história. Falamos de um aprendizado da cultura histórica no museu pela estada momentânea e fugaz, que não se sustenta, na maior parte das vezes, em uma leitura interpretativa dos objetos. Há a instituição e a destruição simultânea de redes tênues de significado, num contexto que não se arquiteta como processo.

Um dos desdobramentos dessa discussão é não aceitar que a "visita ao museu" seja um evento educativo total. Há de se pensá-la como movimento específico e singular, entre outros que consubstanciam o processo educacional de construção de um determinado tema. É dentro de um processo iniciado em sala com discussóes de elementos estruturantes do tema a ser tratado que a visita pode fazer sentido, exigindo igualmente desdobramentos no período pós-visita. A construção de matrizes interpretativas que seja capaz de realizar a leitura informada pela tensão hermenêutico-temporal situa-se neste movimento de usos da cultura histórica para a aprendizagem criativa nos momentos pré e pós-visita, evidentemente também durante a visita.

Não se pode perder de vista que toda a coerência se impóe por esquemas arbitrados, geralmente, pensados na lógica de uma racionalidade 
linear que cristaliza a tudo que toca. Deslocamento e trânsito não podem ser deixados de lado na construção de uma relação educativa afirmativa entre escola e museu.

Superada essa ilusão de transmissão total, o professor poderá se debruçar sobre o novelo de paradoxos e de arbítrios envolvidos nesta trama educativa. Ao fazê-lo, ele não poderá deixar de considerar o valor das práticas culturais de memória e de história em seu enredo social, envolvendo o cotidiano conflitivo e mutável de seus alunos. Desde aqui, o museu emerge como limiar de um processo pedagógico, em que supomos o professor não como refém de um ponto de vista previamente arbitrado. Ao contrário, pressupomos sua capacidade criativa de trabalho com a história, sendo capaz de capturar elementos no curso da vida social para o exercício permanente da pesquisa, pressuposto fundamental da prática docente.

$\mathrm{Na}$ medida em que o museu possa ser pensado como lugar de trânsito e discursos arbitrados, será possível conceber processos educativos que contemplem o estranhamento dos sentidos históricos e memorialísticos por ele propostos. A dessacralização do espaço museal supóe um processo educativo que permita aos sujeitos a experiência de um pensamento sobre as distâncias e a impossibilidade de fazer aparecer sentidos primeiros ou absolutos das coisas expostas. A transumância dos objetos e o trânsito dos visitantes deflagram experiências de desenraizamento que precisam ser consideradas na construção do conhecimento e nas experiências sensíveis que a abordagem educativa do museu provoca.

Supomos uma educação que requer aprendizagem da errância para abranger o pensamento acerca da fluidez do tempo e do esquecimento implicados nos atos de memória. É uma experiência de educação "em deslocamento" o que o museu pode oferecer. Há no museu objetos sem-lugar intrínseco que se oferecem, quando arranjados, ao exercício da imprevisibilidade, da prática do conflito, das mudanças e da experiência de devastação e de limite.

Françoise Choay nos diz que o espaço do museu tornou-se o "gesto arquitetônico" de nossa época: "Os museus são visitados como monumentos" (2006, p. 217). Essa observação traz a exigência de considerar a visita educativa como ambiente revisitado e recomposto para além da circulação passiva pela caixa-monumento do museu. 
Um espaço capaz de fazer pensar e agir acerca da rede dinâmica de interaçôes sócio-temporais. Há nesse lugar, à moda de Babel, uma confluência de trânsitos e de dispersōes temporais de discursos e silêncios. A suposta fixidez do objeto ordenado é colocada em xeque mediante a leitura sempre passível de torçōes, distorções, atualizações, rejeições, reapropriações e desapropriações. Há uma compreensão especular do museu, em que o visitante tem a possibilidade de completar e ressignificar o discurso museal.

Fazer com que esse movimento de tensão hermenêutico-temporal seja apreciado como elemento constituinte do discurso museológico, que dinamiza e dissemina práticas, valores e representaçôes de variabilidade múltipla e complexa que envolvem desde jogos subjetivos de psicologia até conflitos e negociaçōes sociais, parece determinante para a reflexão das possibilidades de exploração educativa dos espaços museais.

\section{Ultrapassagens na relação museu-escola}

O gesto museal pode ser importante para a percepção da dinâmica histórica quando compreendido num quadro sócio-cultural mais amplo. Supomos uma abordagem das complexas interconexōes sociais, políticas, econômicas e culturais, presentes no trabalho do museu, em diálogo com as experiências que os alunos vivenciam na escola e nas práticas sociais. No processo educativo, assim concebido, interconectam-se os registros e as experiências culturais dos alunos e de suas famílias, bem como daqueles grupos de convívio vincados às trajetórias das comunidades em que os museus se inserem.

Ressaltar o que liga o museu à sociedade é uma das questôes mais significativas nesse processo educativo. Do contrário, como será possível compreender a história, supondo para os objetos a clausura das caixas-monumento museais? De novo, é pertinente o exemplo do mimeógrafo, o qual, como objeto em trânsito, está presente na escola e no museu, simultaneamente, mas compondo redes de significaçôes diferenciadas.

Se admitirmos a suposição de que o museu é uma das maneiras possíveis pelas quais a nossa sociedade responde aos apelos de memória e à dissolução do passado, afirmamos os pressupostos de ultrapassagem do objeto como signo de totalidade, do museu como ícone do passado 
e de uma relação museu-escola que pretenda prescindir da dinâmica social para a aprendizagem e a formação das sensibilidades históricas.

Fazer saltar aos olhos o trabalho do museu é um primeiro passo para esta ultrapassagem. Em cada museu visitado é fundamental propiciar o acesso à sua história, à história de suas coleções e às escolhas feitas no decurso de sua formulação como instituição de memória. No momento pré-visita, é significativo garantir o acesso às informações mais amplas possíveis sobre o museu, ao plano de visitação previamente elaborado e às atribuições de cada trabalhador que atua no museu. Fazer exercícios de imaginação acerca do que o museu não expõe é uma das formas de convidar os alunos a este deslocamento face à ilusão de totalidade.

Conceber outros roteiros de visitação, no período pós-visita, também pode favorecer a desconstrução dos sentidos unívocos de objetividade, desativando a armadilha do trajeto pré-definido e do itinerário único. Fazer com os alunos outros planos imaginários de exposição dos mesmos objetos poderá dar realce ao que parecia oculto ou subliminar, explicitando os lugares fabricados pelo museu.

O museu não é capaz de fazer reverberar toda a complexidade da dinâmica histórica e cultural - há, por exemplo, histórias que repicam luto e silenciamento. Propor aos alunos esta investigação ajuda a compreender as razóes, os consensos e os dissensos, pelos quais a sua comunidade de convívio erigiu um museu ou por que razões umas e outras narrativas foram silenciadas e preteridas em seu contexto. Não é sempre possível expor o terror, a humilhação e a barbárie - como no exemplo terrível do holocausto judeu da Segunda Guerra Mundial, em que não seria sensível ou digno corporificar a história (Huyssen, 2000). Há uma função pedagógica do vazio e do silêncio, que se torna mote para a aprendizagem histórica, haja ou não museus.

Afirmamos a fina e tênue tessitura das conexões, tensões e disputas presentes na experiência da vida social, mantendo evidente a possibilidade de fazer ressoar a instável superfície dos objetos, como requer uma educação que não pode prescindir dos limites radicais da alteridade. Em Antes de nascer o mundo, de Mia Couto, diante de uma sepultura reaberta, diz o pai: "- Vê a terra, filho? Parece areia, pedras e torrões. Mas são braços e abraços” (Couto, 2009, p. 51).

$\mathrm{O}$ museu pode ser compreendido como uma instituição que permite aprendizagens para muito além do limite de suas pressuposições 
pedagógicas. Numa visita escolar, a educadora do museu pergunta a um grupo de crianças o que elas vêem diante de uma grande canoa. As respostas não revelam o que é esperado: "um pau, um pau velho, um pedaço de madeira, um tronco de árvore, um toco...”. Apenas no momento em que a educadora se abaixa ela se torna capaz de ver que, de cima, o que lhe parece uma canoa, do ângulo de visão das crianças era coisa diversa. Ao alterar sua perspectiva, a educadora teve a oportunidade de rever sua posição educativa.

O museu pode contribuir decisivamente para a construção de propostas educativas compartilhadas com a escola, em que a criatividade seja considerada valor crucial. Os encontros com professores podem se fundamentar na interpretação cultural e de significação, favorecendo a análise da trajetória social dos objetos até a estada no museu, a história do uso e desuso dos objetos, dos impasses e das perspectivas da educação para compreender a história, num mundo em que o descarte e a morte súbita dos objetos tornaram-se a tônica.

A criação de roteiros específicos que dialoguem com as demandas da escola ou a proposição de rotas singularizadas para a análise de um tema pode permitir superar pressupostos de uma ação educativa que pretenda se esgotar numa única visita, convidando todos os sujeitos ao exercício do protagonismo no processo da visita. $\mathrm{O}$ momento da visita tornar-se-ia um laboratório surpreendente de inquiriçôes e formulaçôes. O momento pós-visita poderia desestabilizar as suposições inicialmente projetadas no plano museal, favorecendo a percepção dos impactos, as releituras e os novos usos que se enunciam na passagem pelo museu e em sua ultrapassagem.

Trata-se de uma educação que não pode prescindir do deslocamento, de uma aprendizagem do ser nômade em um ambiente de nomadismos. O museu não é lugar-final, mas lugar de trânsito. Como lugar de transfigurações, ele não poderá comportar sentidos unívocos, nem mesmo para aqueles objetos de sedutora estabilidade $\mathrm{O}$ museu é lugar de ultrapassagens, em que emergem relações dinâmicas e intricadas entre os sujeitos na experiência de aprender e sentir os enovelamentos dos tempos.

Recebido em junho de 2009 e aprovado em novembro de 2009. 
Referências

ADORNO, T. Educação e emancipação. Rio de Janeiro: Paz \& Terra, 1995.

BRAUDEL, F. História e ciências sociais. Lisboa: Editorial Presença, 1982.

CLARK, A. Supersizing the mind: embodiment, action, and cognitive extension. Oxford: Oxford University Press, 2008.

CHOAY, F. A alegoria do patrimônio. São Paulo: Estação Liberdade; UNESP, 2006.

COUTO, M. Antes de nascer o mundo. São Paulo: Companhia das Letras, 2009.

HEIDEGGER, M. Ser e tempo. Petrópolis: Vozes, 1988.

HEIDEGGER, M. A tese de Kant sobre o ser. In: Martin Heidegger. Conferências e escritos filosóficos. São Paulo: Nova Cultural, 1999. p. 225-248.

HUYSSEN, A. Seduzidos pela memória: arquitetura, monumentos, mídia. Rio de Janeiro: Aeroplano, 2000.

LOPES, D.R.N. Platão - A República, livro x: tradução, ensaio e comentário crítico. 2002. Dissertação (Mestrado em Linguística) - Instituto de Estudos da Linguagem da Universidade Estadual de Campinas. Campinas.

MERLEAU-PONTY, M. O visivel e o invisivel. São Paulo: Perspectiva, 2000 .

RICOEUR, P. Temps et récit. 3v. Paris: Seuil, 1983-1985.

RICOEUR, P. Les temps et lês philosophies. Paris: Unesco; Payot, 1978.

SARLO, B. Tempo passado; cultura da memória e guinada subjetiva. São Paulo: Companhia das Letras; Belo Horizonte: Editora da UFMG, 2007.

VIEIRA, T. Homero e a tradição oral. In: Homero. A ira de Aquiles: Canto I da Íliada de Homero. São Paulo: Nova Alexandria, 1994. p. 77-94. 